\title{
Pedagogia Intuitiva da Escola Elementar de Pestalozzi: como se ensinava Aritmética?
}

\author{
Pestalozzi’s Intuitive Pedagogy of Elementary School: how \\ Arithmetic was taught?
}

Marcus Aldenisson de Oliveira*

\begin{abstract}
Resumo
Este artigo tem por objetivo compreender o arranjo metodológico no ensino da Aritmética na escola elementar de Pestalozzi. Interessa saber como se ensinava Aritmética na escola elementar pestalozziana? Ao transformar alguns textos de Pestalozzi em documentos, notei que o educador suíço sistematizou uma teoria pedagógica que mudou o estatuto da tríade: aluno-saber-professor. Trata-se de uma pedagogia assentada na atividade do espírito humano manifestada pela intuição. Denominei-a de pedagogia intuitiva. Uma pedagogia que psicologizou o saber elementar, sob o pretexto de seguir a natureza humana através das intuições sensível e racional. Colados na forma mais simples, os saberes da Aritmética foram reduzidos, de algum modo, aos elementos palpáveis, visíveis e acessíveis a todos os sentidos.
\end{abstract}

Palavras-chave: Aritmética. Pedagogia Intuitiva. Pestalozzi.

\begin{abstract}
This article aims to understand the methodological arrangement in Pestalozzi's arithmetic teaching in elementary school. The question arises: How arithmetic was taught in the Pestalozzi elementary school way? By transforming some of Pestalozzi texts in documents, I noticed that the Swiss teacher systematized a pedagogical theory that changed the status of the triad: student-knowledge-teacher. This is a pedagogy based in the activity of the human spirit manifested by intuition. I called it intuitive pedagogy. A pedagogy that psychologized the elementary knowledge, under the pretext of following human nature through the sensitive and rational intuitions. Put together in the simplest form, the knowledge of arithmetic has been reduced, in some way, to the tangible, visible and accessible elements to all senses.
\end{abstract}

Keywords: Arithmetic. Intuitive Pedagogy. Pestalozzi.

\section{Introdução}

“O nome de Pestalozzi é mencionado frequentemente, mas poucos o leem e continuam conhecendo muito mal tanto sua obra quanto seu pensamento [...]", tais foram as primeiras palavras que Michel Soëtard (2010, p. 11) começou seu livro, publicado no Brasil pelo MEC, na Coleção Educadores.

\footnotetext{
* Doutor em Ciências pelo Programa de Pós-Graduação em Educação e Saúde da Universidade Federal de São Paulo (UNIFESP), Campus Guarulhos/SP. Endereço para correspondência: Rua Doutor Aureliano Duarte, $\mathrm{n}^{\circ}$ 218, casa 18, Jardim Peri, São Paulo-SP, CEP 02632-020. E-mail: marcus_aldenisson @ hotmail.com.
} 
Com o propósito de ir na contramão do que disse Soëtard, ou seja, a fim de conhecer a obra pedagógica e o pensamento de Pestalozzi, este artigo ${ }^{1}$ admite a seguinte problemática: Como se ensinava Aritmética na escola elementar pestalozziana? O modo como a problemática está posta exige o acesso a documentos da época. Pois bem, as fontes utilizadas para a escrita deste artigo atendem essa exigência.

A partir de um levantamento em algumas bibliotecas da França, montei um corpus documental relativamente inédito, ou, melhor dizendo, de textos poucos conhecidos no Brasil. Citam-se apenas dois deles ${ }^{2}$ : Méthode théorique et pratique de Pestalozzi pour l'éducation et l'instruction élémentaires, publicado em francês pelo próprio Pestalozzi, em 1826; Introduction des mathématiques dans l'instruction populaire, pequeno artigo de 1848, escrito por Joseph Schmid, ex-aluno e professor de Matemática nos institutos de Pestalozzi por quase duas décadas. Esses dois documentos mostram como o método de Pestalozzi conduzia o ensino da Matemática na escola elementar.

Outros textos, transformados por mim em documentos ${ }^{3}$, os quais foram escritos por pessoas que vivenciaram o dia a dia nos institutos educacionais de Pestalozzi, oferecem uma visão mais geral da sua teoria pedagógica ${ }^{4}$. Cumpre ressaltar que também tive acesso a muitos outros escritos do próprio Pestalozzi, a exemplo: cartas, projetos de implantação de uma Escola Normal da Suíça, discursos para os pais dos alunos que estudavam nos institutos, etc. Tal acesso só foi possível graças ao trabalho do Centro de Documentação e Pesquisa de Pestalozzi, em Yverdon-les-Bains, na Suíça, fundado em 1977, que publicou em francês uma coleção intitulada Ecrits sur la Méthode ${ }^{5}$. Enfim, tentei ao máximo me aparelhar de textos da época da sistematização da teoria pedagógica de Pestalozzi, com o propósito de ter

\footnotetext{
${ }^{1}$ Inserido no projeto de cooperação (CAPES/COFECUB) entre os países Brasil e França, este texto é fruto dos resultados parciais de uma pesquisa de doutorado que tem por tema a constituição da Aritmética escolar do ensino primário a partir da Pedagogia Moderna. Desenvolvida por meio de um estágio na França, a pesquisa esteve sob orientação do Professor Doutor Marc Moyon. No Brasil, a investigação é desenvolvida sob orientação do Professor Doutor Wagner Rodrigues Valente.

${ }_{2}^{2}$ Ambos os textos foram consultados na Bibliothèque Nationale de France - BnF.

${ }^{3}$ Os textos de Pestalozzi e das pessoas que presenciaram de alguma forma a sistematização da pedagogia intuitiva são testemunhos de uma realidade vivida, a qual é apresenta como vestígios que precisam ser compreendidos. Amparado nos escritos de Le Goff (1994), transformei tais textos em documentos, isto é, como "fundamento do fato histórico, como prova histórica" (LE GOFF, 1994, p. 535).

${ }^{4}$ Citam-se os seguintes livros: Exposé de la méthode élémentaire de H. Pestalozzi..., de 1805, com autoria do amigo pessoal de Pestalozzi o pastor Daniel-Alexandre Chavannes (disponível na Bibliothèque Nationale de France - BnF); e Esprit de la méthode d'éducation de Pestalozzi..., publicada em $1812 \mathrm{em}$ dois tomos, com autoria do político e crítico pedagógico francês Marc Antonie Jullien (disponível na Bibliothéque SainteGeneviève - BSG). Marc Jullien, para escrever essa obra estudou no instituto de Pestalozzi, em Yverdon, durante dois anos.

${ }^{5}$ Essa coleção é composta atualmente por cinco volumes publicados entre 2008 e 2013. Assim, a partir desse momento todas as vezes que fizer referências aos artigos contidos em tais volumes, elas serão assim indicadas: artigos do volume I (2008, [ano do artigo]); volume II (2009a, [ano do artigo]); volume III (2009b, [ano do artigo]); volume IV (2011, [ano do artigo)]; volume V (2013, [ano do artigo]).
} 
informações que permitissem alcançar o objetivo deste artigo: Compreender o arranjo metodológico no ensino da Aritmética na escola elementar de Pestalozzi. Vamos ao que me foi possível captar e sintetizar nas páginas deste artigo...

\section{A instrução elementar na pedagogia intuitiva de Pestalozzi: aluno-saber-professor, uma trilogia em mudança}

Para merecer a qualificação de elementar, a instrução da criança na idade escolar deve aparecer, de uma parte, como um desenvolvimento completo das forças morais, intelectuais e físicas da natureza humana, conduzida conscientemente $e$ fundada sobre a essência das disposições humanas. Ela deve, de outra parte, estar em acordo com a situação exterior da criança, com o contexto no qual ela vive, tomada em toda sua verdade. Toda sua atividade nessa idade é essencialmente um esforço consciente visando prosseguir e completar, por um ensino e uma educação conformes às leis da psicologia, o curso natural do seu desenvolvimento ${ }^{6}$ (PESTALOZZI, 2009b [1812] p. 39-40).

A epígrafe é longa, mas reveladora. Pestalozzi considerava que as leis psicológicas dariam as diretrizes do ensino e da educação da criança. A instrução elementar visava desenvolver as forças morais, intelectuais e físicas da criança, considerando a vida cotidiana dessa criança, de modo que o desenvolvimento de tais forças seguisse seu curso natural. Mas afinal, como Pestalozzi pensava a Educação? E a instrução? E o saber elementar? Essas e outras questões conduzem a escrita deste tópico.

Desde o título deste artigo, uma pergunta merece ser levantada: o que estou chamando de pedagogia intuitiva? Vamos por partes e sempre tomando os escritos de Pestalozzi como referências. Começando: o que entendo por pedagogia? Para mim, pedagogia não é método. A pedagogia, tal como entendo, se distancia do que afirmam os didáticos: “[...] a pedagogia se ocupa dos métodos de ensino ou da transmissão de saberes” (BRU, 2015, p. 5). Por outro lado, a concepção de pedagogia que admito se aproxima dos escritos de André Chervel (1990, p. 183), "a pedagogia, longe de ser um lubrificante espalhado sobre o mecanismo, não é senão um elemento desse mecanismo, aquele que transforma os ensinos em aprendizagens". Chervel buscou desfazer a imagem que geralmente temos da pedagogia: um lubrificante dos conhecimentos científicos. Essa imagem é construída, disse ele, porque "na opinião comum, a

\footnotetext{
6 “Pour mériter le qualificatif d'élémentaire, l'instruction de l'enfant d'âge scolaire doit apparaître, d'une part, comme un développement complet des forces morales, intellectuelles et physiques de la nature humaine, conduit consciemment et fondé sur l'essence des dispositions humaines. Elle doit, d'autre part, être en accord avec la situation extérieure de l'enfant, avec le contexte dans lequel il vit, pris dans toute sa vérité. Toute son activité à cet âge est essentiellement un effort conscient visant à poursuivre et à parachever, par un enseignement et une éducation conformes aux lois de la psychologie, le cours naturel de son développement."
} 
escola ensina as ciências, as quais fizeram suas comprovações em outro local" (CHERVEL, 1990, p. 182).

O combate contra a ideia de que pedagogia é um lubrificante dos conhecimentos científicos vem desde há muito tempo. De acordo com Michel Soëtard (2001, p. 105, grifos do autor) é justamente isso "que recusa Pestalozzi, toda a redução da pedagogia a uma aplicação das leis gerais que colocam à luz as ciências humanas, e mais largamente o saber universal do homem (a filosofia)". Veja-se que também para Pestalozzi, pedagogia não é método.

A partir dos escritos de Pestalozzi passei a entender que o aluno, o saber e o professor não são restritamente os objetos de interesse da pedagogia, mas a atividade que faz essa trilogia se articular atendendo a uma harmonia. Não se trata de qualquer atividade, mas aquela que emerge da natureza humana. Daí, Pestalozzi considerou ser a intuição uma faculdade própria do espírito humano e fundamento de todo conhecimento produzido com as impressões sensíveis das coisas. É isso que chamo de pedagogia intuitiva: uma pedagogia assentada na própria atividade do espírito humano manifestada pela intuição porque "tudo isso que a juventude aprende deve ser fruto da sua própria atividade, uma criação viva que ela produz por si própria"7 (PESTALOZZI, 2008, [1808], p. 159).

Pestalozzi não tirou essa conclusão do dia para a noite. A trajetória de vida dele influenciou na sistematização da sua pedagogia. Johann Heinrich Pestalozzi nasceu em Zurique (Suíça), em 12 de janeiro de 1746. Em Neuhof, no ano de 1774, ele instalou um centro educativo para a educação de meninos pobres que trabalhavam também na fiação e tecelagem de algodão. Esteve lá até 1780. Entre 1780 e 1798, Pestalozzi tornou-se participante de movimentos revolucionários e devotou-se à atividade literária (MONROE, 1968). De 1800 a 1804, dois outros institutos, um em Stans e outro em Burgdorf, foram criados por Pestalozzi. Nesses institutos, o suíço continuou com a elaboração e experimentação dos princípios da sua pedagogia. Em 27 de junho de 1800, ele destinou à Sociedade de Amigos da Educação um escrito contendo justamente os princípios dessa pedagogia em experimentação. Nesse escrito, apareceu pela primeira vez o conceito de intuição, além do objetivo de Pestalozzi que era psicologizar a educação ${ }^{8}$.

Tempos depois, em 1805, Pestalozzi transformou o castelo de Yverdon, em Neuchâtel, cedido pelo governo da Suíça Francesa, no seu mais novo centro de experimentação e de

\footnotetext{
7 "Tout ce que la jeunesse apprend doit être le fruit de sa propre activité, une création vivante qu'elle produit librement par elle-même."

${ }^{8}$ Cf. o texto de Loïc Chamel (2009).
} 
elaboração das suas ideias educacionais. No discurso proferido aos pais das crianças que lá estudavam, Pestalozzi disse que a vida no instituto se resumia em duas palavras: elevação do espírito e aprendizagem. Nesse instituto, ele continuou a dizer, "visa-se uma elevação mais vasta e global, visa-se a aprendizagem de acordo com a natureza, em uma vida livre e autônoma sob o olhar de todos"9 (PESTALOZZI, 2008, [1808], p. 138-139). No castelo de Yverdon existia um sistema escolar completo. Digo completo porque lá tinha: Escola Primária; Escola Secundária; Escola Especial; Escola Normal; Escola Experimental; e a Educação de surdo-mudo de nascença. No fundo, como disseram Mérian, Girard e Trechsel (1810, p. 85), "o Instituto quer ser a universidade da infância"10. Mas, nessa universidade, cada escola tinha sua(s) finalidade(s).

- A Educação de surdo-mudo recebia os direcionamentos pedagógicos da Escola Experimental que se destinava aos experimentos da marcha e desenvolvimento da natureza humana. Para isso, aplicava-se um método de ensino que se baseava na vida interior e exterior da criança;

- A Escola Normal, destinava-se a formar professores e professoras a fim de educar e instruir as crianças ${ }^{11}$;

- A Escola Especial ocupava-se da instrução preparatória para a indústria e artes, da educação das mulheres para os deveres de esposa e mãe, e da instrução das ciências pedagógicas;

- A Escola Secundária envolvia-se com a extensão e aplicação dos conhecimentos adquiridos no ensino de cada ramo da ciência;

- A escola primária tinha uma dupla finalidade: despertar as forças físicas, morais e intelectuais, bem como desenvolver tais forças na elaboração do saber próprio a cada matéria $^{12}$.

Pestalozzi morreu aos 81 anos, deixando um legado educacional que até hoje está nos grandes centros de pesquisa acerca do conhecimento educativo. Como se viu, essa herança educacional foi produzida em locais e em momentos distintos. Suas ideias pedagógicas elaboradas e experimentadas nos seus centros educacionais foram sistematizadas e publicadas

\footnotetext{
9 "On vise une élévation plus vaste et globale, on vise l'apprentissage selon la nature, dans une vie libre et autonome sous le regard de tous."

10 "L'institut veut être l'université de l'enfance."

${ }^{11}$ Em 1806, Pestalozzi fez um projeto com o propósito do governo suíço criar uma Escola Normal na vila Canton de Vaud. O projeto expõe os fundamentos pedagógicos da teoria de Pestalozzi, os quais seriam praticados em tal escola. A concretização do projeto ocorreu, e Frédéric Gauthey, um ex-aluno seu, dirigiu a primeira escola normal daquela vila. (Cf. Pestalozzi (2011, [1806])).

${ }^{12}$ Para um estudo mais detalhado do funcionamento de cada uma dessas escolas no instituto de Yverdon, veja Jullien (1818a, 1818b).
} 
através de vários artigos e livros. Citam-se alguns: Velada de uma Ermitaño (1780); Léonard et Gertrude (1781); Mes recherches sur la marche de la nature dans l'évolution du genre humain (1797); Comment Gertrude instruit ses enfants (1801); Le Manuel des mères: 1'ABC de l'intuition, ou enseignement intuitif des rapports de mesure et numériques (1803-1804); Cartas sobre educación infantil (1818-1819); Chant du Cygne (1827).

Um dos objetivos de Pestalozzi era abolir algumas heranças "[...] das escolas tradicionais que forçam os alunos a ficarem sentados, imóveis e calados"13 (PESTALOZZI, 2008, [1808], p. 149). Para o alcance disso, ele sistematizou uma proposta pedagógica que mudou o estatuto do aluno, do professor e do saber. Tal transformação esteve atrelada ao ensino e aprendizado pela intuição. O suíço considerou a intuição a partir de duas perspectivas: uma sensível (ou exterior) e outra racional (ou interior). Numa carta escrita para o seu amigo Gessner, é possível saber claramente o que ele chamava de intuição sensível: “Amigo, a intuição sensível [...] é considerada como o ponto de onde parte o ensino, [...]. Ela não é nada mais que a simples presença dos objetos exteriores perante os sentidos e o simples despertar da consciência das impressões que eles produzem"14 (PESTALOZZI, 2013, [1801], p. 142).

Não só isso. A intuição para Pestalozzi não se limitava apenas em manifestar as impressões das coisas, mas também em impulsionar as primeiras ações da inteligência. Por assim entender, a intuição sensível foi elevada ao nível de arte da intuição caracterizada como o julgamento e raciocínio das impressões recebidas. Anos mais trade, em 1826 para ser mais preciso, Pestalozzi chamou essa arte da intuição de intuição interior. Para ele, "a inteligência tem, desde o início, uma dupla direção: ela vai da vista do objeto material a um raciocínio sobre esse objeto, ou seja, da intuição exterior à intuição interior, e reciprocamente, do raciocínio ela desce aos objetos exteriores"15 (PESTALOZZI, 1826, p. 12). O desenvolvimento intelectual da criança coloca em atividade essa dupla perspectiva de intuição e vice-versa. Com esse pensamento, ele organizou um Método ${ }^{16}$ baseado pelas impressões

\footnotetext{
13 “[...] dans les écoles traditionnelles qui forcent les élèves à rester assis, immobiles et silencieux, [...].”

14 “Ami, l'intuition sensible [...] elle est considérée comme le point d'où part l'enseignement, [...]. Elle n'est rien d'autre que la simple présence des objets extérieurs devant les sens et le simple éveil de la conscience des impressions qu'ils produisent."

15 "L'intelligence a, dès le commencement, une double direction : elle va, de la vue de l'objet matériel, à un raisonnement sur cet objet, c'est-à-dire de l'intuition extérieure à l'intuition intérieure, et réciproquement, du raisonnement elle redescend aux objets extérieurs."

${ }^{16}$ Aqui cabe uma ressalva. Nos seus textos, Pestalozzi normalmente escrevia a palavra método com a letra "m" em maiúscula: Método. Não se trata de método de ensino propriamente dito. A palavra Método, em Pestalozzi, deve ser entendida como um conjunto de leis psicológicas e pedagógicas organizadas em torno da tríade coração-cabeça-mão, ou melhor, educação moral-intelectual-física. (Cf. Michel Soëtard, 2008).
} 
que tocam os sentidos e pelo desenvolvimento natural das faculdades. Um Método que fazia o ensino progredir conforme os fundamentos naturais e psicológicos. Disse Pestalozzi:

E esse Método, eu não o inventei, ele se encontrava de toda eternidade na natureza humana e ele se revela por si. É o simples fato de fundar o ensino sobre os elementos do saber que são o número, a forma e a palavra, seguindo em direção que não estava ainda claramente definida. [...]. O Método se constrói por ele mesmo, no espírito humano ${ }^{17}$ (PESTALOZZI, 2008 [1805], p. 87-88).

O que ele denomina de elementos do saber? Ora, se a intuição sensível dos objetos é o ponto de arranque do ensino, então ele chama de elemento a manifestação da força primitiva capaz de despertar a consciência para exprimir as impressões recebidas pelos sentidos. A princípio, um objeto aparece de modo obscuro e confuso aos sentidos e faculdades da criança. Os primeiros passos para vencer esse obstáculo é saber identificar o número de objeto que se tem em vista; em seguida, conhecer a forma desse objeto para distingui-lo de outros já conhecidos; e dar um nome. Por isso, Pestalozzi chegou à conclusão de que todos os objetos concretos são necessariamente representados pelo número, forma e palavra - os três principais elementos do saber.

Entretanto, esses elementos emergem na consciência de maneiras distintas. De acordo com Pestalozzi (2013, [1801]), as impressões sensíveis do número e da forma precedem a expressão da palavra. Isto é, a forma e o número são impressões próprias a todos os objetos, as quais podem ser apreendidas na intuição sensível. Diferentemente, a palavra é uma construção intelectual que permite a criança se expressar com precisão sobre os objetos. A palavras serve de fio condutor para formação das noções claras. O seu fim é fazer a criança se elevar das percepções confusas para as concepções claras. Dado a isso, o Método não é uma invenção pois ele se assenta na própria natureza humana. Mas a natureza humana da qual se fala é aquela que se apresenta não como ela deve-ser, mas como ela é. Para além disso, fala-se de um método denominado de intuitivo para o ensino dos elementos do saber.

Assim, admito como objetivo para este tópico: compreender o arranjo lógico que orienta o ensino a partir do método intuitivo de Pestalozzi. Não se pode tratar de método de ensino deixando à margem a disposição metódica na progressão do ensino. Por assim também entender, o educador suíço ressaltou que "a característica desse método de formação consiste que ele parte sempre do mais simples e progride para as coisas complicadas e mais difíceis

\footnotetext{
17 "Et cette méthode, je ne l'ai pas inventée, elle se trouvait de toute éternité dans la nature humaine et elle s'est révélée d'elle-même. C'est le simple fait de fonder l'enseignement sur les éléments du savoir que sont le nombre, la forme et le mot, en suivant une direction qui n'était pas encore clairement définie. [...]. La méthode se construit d'elle-même, dans l'esprit humain."
} 
por uma série continua de patamares quase imperceptíveis"18 (PESTALOZZI, 2009b, [1812], p. 43). Tem-se caracterizado que o simples é tudo aquilo captado pela intuição sensível que a criança seja capaz de se expressar. Quando se fala do simples, por consequência, pensa-se no complexo. Do ponto de vista pedagógico, a simplificação de algo exige, por força do termo, a graduação das dificuldades até a complexidade.

Trata-se assim de perceber as coisas e o conhecimento em si, como um todo vivo e orgânico, cujos elementos se imbricam harmoniosamente de acordo com as leis necessárias e eternas e que se desenvolvem em sua complexidade a partir de uma origem simples, a fim de que o ensino se desdobre a partir dessa percepção como o complexo se funda sobre o simples que o constitui ${ }^{19}$ (PESTALOZZI, 2008, [1808], p. 151).

A citação mostra que na pedagogia pestalozziana o complexo não é referência para determinar o simples. Ao contrário, as percepções complexas se constituem dos elementos simples, porque as coisas mais complicadas derivam das mais simples. Qual a origem dos elementos do saber qualificados de simples? Em qual ordem eles devem avançar do simples para o complexo? Segundo Pestalozzi (2009b, [1818], p. 94), “a simplificação dos meios de formação do povo não é possível sem um sério aprofundamento das bases gerais do saber e das capacidades do povo" 20 . Se o método se ampara no desenvolvimento natural das ideias, então temos que a simplificação dos três elementos do saber deve necessariamente ser submetida aos fundamentos psicológicos. Dessa forma, a graduação das dificuldades avança do simples para o complexo a partir de uma ordem psicológica, sob o pretexto de seguir a natureza humana. Essa é uma das marcas da pedagogia pestalozziana: dar aos três elementos do saber (o número, a forma e a palavra) a forma mais simples. Em outras palavras: colocar esses saberes na forma elementar.

Etimologicamente, a palavra elementarius em latim significa elementos, que por sua vez é remetida à expressão elementar. Na esteira das definições, o Dictionnaire de la langue française (Le Petit Robert) confere que elementar é isso "que se relaciona a um elemento. Que contém, que concerne os primeiros elementos de uma ciência, de uma arte" (ROBERT, 2003, p. 851). Na sua pedagogia, Pestalozzi (2009b, [1818]) considerou que os elementos

\footnotetext{
18 "Le propre de cette méthode de formation consiste en ce qu'elle part toujours du plus simples et progresse vers les choses compliquées et plus difficiles par une série continue de paliers presque imperceptibles."

19 "Il s'agit en fait de percevoir les choses et la connaissance elle-même comme un tout vivant et organique, dont les éléments s'imbriquent harmonieusement selon des lois nécessaires et éternelles et qui se développent dans sa complexité à partir d'une origine simple, afin que l'enseignement se déploie à partir de cette perception comme le complexe se fonnde sur le simple qui le constitue."

20 "Et la simplification des moyens de formation du peuple n'est pas possible sans un sérieux approfondissement des bases générales du savoir et des capacités dans le peuple."
} 
seriam utilizados ora como meios de desenvolvimento e exercícios das forças naturais do espírito humano, ora como matérias das ciências e das artes.

Nesse sentido, o elementar na obra pedagógica pestalozziana é constituído através de meios educativos e instrutivos organizados psicologicamente. $O$ saber elementar em Pestalozzi aparece com o seguinte status: ele é psicologizado, ou seja, fundamentado nas disposições e forças da natureza humana ${ }^{17}$. Além disso, esse saber elementar tem duplo alcance: através das intuições sensível e racional, visa-se a formação do espírito humano conforme a natureza; a partir das noções elementares, caracterizam-se as primeiras aprendizagens dos elementos das ciências e das artes.

A identificação desse duplo alcance do saber elementar pestalozziano só me foi possível quando notei a primazia da educação em relação à instrução. De acordo com Pestalozzi (2009b, [1812], p. 23), “[...] toda verdadeira educação deve se basear, de uma parte, desde o seu início, sobre as disposições iniciais e as forças da natureza humana e, de outra parte, sobre os elementos particulares a cada ciência e a cada arte"18. A educação tem como finalidade a formação do homem na sua integralidade assentada nas disposições morais, intelectuais e físicas. A instrução é um meio de manifestação dessas disposições, adquirindo assim as noções elementares de cada ciência e cada arte. Pestalozzi denominou de formação elementar $^{19}$ aquela que se divide em: educação elementar moral, intelectual e física.

Com o fim de aperfeiçoar as faculdades naturais do pensar, sentir e agir, "a educação elementar moral não é outra coisa que o puro desenvolvimento do querer humano" (PESTALOZZI, 1826, p. 79, grifos do autor). Essa educação manifesta aquelas faculdades a partir de dois planos: o real, quando a moral é exteriorizada através das ações no mundo físico; e o ideal, quando a moral é despertada no íntimo do homem por meio dos sentimentos do amor materno, do amor divino, da confiança (PESTALOZZI, 1826). Para exemplificar, podemos considerar que o comportamento é uma formação moral instigada pelo mundo real. Afinal, os princípios de comportamento podem ser explicados e ensinados. Diferentemente, o sentimento de crer e amar não se elevam através de explicações aleatórias sobre a fé e o amor,

\footnotetext{
${ }^{21}$ Para uma reflexão mais aprofundada sobre o assunto, veja Alain Trouvé (2008).

22 "“[...] toute véritable éducation doit se fonder, d'une part, dès ses débuts, sur les dispositions initiales et les forces de la nature humaine et, d'autre parte, sur les éléments particuliers à chaque science et à chaque art."

23 “"...] la formation élémentaire n'est rien d'autre qu'une expression vivante de la nécessité du double point de vue auquel il faut se placer, comme je l'ai dit tout à l'heure, quand on parle de formation et d'éducation" (PESTALOZZI, 2009b, [1818], p. 61). E disse mais: “je vais plus loin. L'idée mûrie de la formation élémentaire exige indubitablement que la connaissance scientifique procède du développemente préalable des forces de la nature humaine" (p. 66). Cf. também Pestalozzi (2009b, [1812], p. 23).

24 "L'éducation élémentaire morale n'est autre chose que le pur développement du vouloir humain, [...]."
} 
mas através de vivências efetivas dos mesmos, isto é, como ato de pensar, de sentir afeto por alguém.

“A educação elementar intelectual, do seu lado, não é também nada de outra coisa que o puro desenvolvimento do saber humano"21 (PESTALOZZI, 1826, p. 81). Da mesma forma que a moral, as faculdades que configuram os elementos do saber são impulsionadas em dois mundos: o visível/exterior, quando as impressões atingem os sentidos; e o invisível/interior, quando se exige a consciência das impressões. Tal consciência suplica e instiga ao mesmo tempo o saber reunir, o saber separar, o saber comparar e o saber julgar. Esses saberes são resultados das ações que as impressões primitivas jogam sobre a vida interior. Para que a educação elementar intelectual alcance o seu objetivo, requer-se o respeito a dois princípios: $1^{\circ}$ ) que a ação das impressões da natureza sobre a razão tenha uma direção psicológica; $2^{\circ}$ ) que esse direcionamento psicológico das impressões seja configurado pela própria natureza humana a fim de manifestar todas as forças do espírito e da razão (PESTALOZZI, 1826). Harmonizar o desenvolvimento do saber humano seria conciliar esses dois princípios em reciprocidade um com o outro e, por consequência, a vida exterior com a interior.

Em se tratando da unidade interior, "a educação elementar física não é outra coisa que o desenvolvimento psicológico do poder e das diversas forças físicas" (PESTALOZZI, 1826, p. 83). Desenvolvida quando a criança está em atividade, a faculdade física tem assim como arranque a ação, o movimento. Os exercícios corporais aumentam as forças do espírito. Por meio da atividade, as forças naturais se desenvolvem. Essa educação elementar tem por fim dar à criança os elementos necessários para sua autonomia física: poder de agir, poder fazer. No fundo, essa faculdade se desenvolve na criança como resultado da sua própria atividade.

A formação elementar por meio da educação moral, intelectual e física resultou numa lei universal e invariável da natureza humana: "que os sentidos e as faculdades da criança sejam postos em ação, [pois] quanto mais se aumenta a ação da criança simultânea aos seus órgãos mais as obras do espírito se tornam notáveis"22 (PESTALOZZI, 1826, p. 24). Tem-se assim uma teoria pedagógica que aspira conformar educação e instrução à natureza humana para que cada aluno se desenvolva por si mesmo. Nessa articulação, a própria condição de aluno foi transformada. Se nas escolas tradicionais, como disse Pestalozzi, o aluno era forçado a ficar sentado, imóvel e calado, na escola elementar pestalozziana o aluno era visto na sua

\footnotetext{
25 "L'éducation élémentaire, de son coté, n'est aussi rien autre chose que le pur développement du savoir humain, [...]."

26 "Une loi universelle et invariable; c'est que les sens et les facultés de l'enfant soient mis en action; plus on augmente dans l'enfant l'action simultanés de ses organes, plus les oeuvres de son esprit deviennent remarquables."
} 
condição de criança. Essa mudança ocorreu porque o Método considerava a criança um ser ativo. O suíço explica como seu Método enxergava a criança. Saibamos:

Longe de a considerar como uma tábua rasa sobre a qual se deve escrever, como um vaso vazio que deve completar, ele [o Método] a enxerga [isto é, ver a criança] como uma força real, viva, ativa por si própria, que desde o primeiro momento da existência opera em organização e como um corpo orgânico sobre seu próprio desenvolvimento e sobre sua própria extensão; que ela mesma gera e concebe; e que forma e molda-se ao mesmo tempo que produz ${ }^{23}$ (PESTALOZZI, 1826, p. 59-60).

Para não extrapolar nas interpretações, mais uma citação.

Tudo isso que a juventude aprende deve ser fruto da sua própria atividade, uma criação viva que ela produz livremente por si mesma. [...]. Todas as forças das crianças são estimuladas simultaneamente, de modo que trabalham sem se fadigar, porque fornecem esforços sem restrições. Elas se sentem então perfeitamente bem e entregam-se às suas atividades com alegria. Elas aprendem com prazer, [...], porque a matéria a aprender é adaptada às forças de cada um e não se passa a qualquer coisa mais complexa e mais difícil sem que a criança tenha adquirido as mais altas capacidades de atenção, de discernimento e de reflexão; porque tudo isso que é ensinado articula-se ao desenvolvimento da criança e em relação a isso que ela já sabe; porque a criança vive no meio de tudo isso que aprende ${ }^{24}$ (PESTALOZZI, 2008, [1808], p. 159).

E concluiu, dizendo:

A criança no Método é colocada inicialmente, em todo isso que ela aprende, no ponto central. A partir daí, ela pode ampliar seu horizonte em todas as direções, livremente e ao infinito, ela pode ir sem nenhuma limitação tão longe e tão profundo o quanto seja capaz ${ }^{25}$ (PESTALOZZI, 2008, [1808], p. 160).

Ao considerar a criança uma força ativa e ponto central do Método, em que todo aprendizado é fruto da sua própria atividade no meio em que vive, vê-se, contudo, o estatuto do saber sendo transformado. Se a criança vive no meio de tudo isso que ela aprende, então o saber é construído na prática da vida cotidiana. Ou seja, o conhecimento é adquirido pela prática. Não qualquer prática, mas aquela condicionada ao que Pestalozzi denominou de savoir-faire. Na criança, o saber-fazer "resulta do puro desenvolvimento de suas próprias

\footnotetext{
27 "Loin de le considérer comme une table rase sur laquelle il faut écrire, comme un vase vide qu'il faut remplir, elle le regarde au contraire comme une force réelle, vivante, active par elle-même, qui, dès le premier moment de l'existence, opère en organisant et comme un corps organique sur son propre développement et sur sa propre extension; qui engendre de même qu'elle conçoit; et qui forme et façonne de même, et dans le temps même qu'elle produit."

28 “Tout ce que la jeunesse apprend doit être le fruit de sa propre activité, une création vivante qu'elle produit librement par elle-même. [...]. Toutes les forces des enfants sont stimulées simultanément, si bien qu'ils travaillent sans se fatiguer, car ils fournissent des efforts sans contrainte. Ils se sentent alors parfaitement bien et s'adonnent à leurs activités avec un zèle joyeux. Ils apprennent avec plaisir, [...], parce que la matière à apprendre est adaptée aux forces de chacun et que l'on ne passe à quelque chose de plus complexe et de plus difficile qu'au moment où l'enfant a acquis de plus hautes capacités d'attention, de discernement et de réflexion; parce que tout ce qui est enseigné s'enracine dans le dévellopement naturel de l'enfant et reste en relation avec ce qu'il sait déjà; parce que l'enfant vit au milieu de tout ce qu'il apprend."

29 'L'enfant de la mèthode est placé d'emblée, dans tout ce qu'il apprend, au point central. A partir de là, il peut élargir son horizon dans toutes les directions, librement et à l'infini, il peut aller sans aucune limitation aussi loin et aussi profond qu'il en est capable."
} 
forças e não de uma aprendizagem aleatória",26 (PESTALOZZI, 2009a, [1805], p. 28). Para além da instrução, fala-se de um saber-fazer como princípio de formação interior com vistas à satisfação das necessidades e dos desejos do ser. Por isso, disse ele: "eu não devo deixar subsistir essa lacuna. Do saber sem saber-fazer: esse é talvez o presente mais formidável que um gênio malfazejo tenha feito à nossa geração"27 (PESTALOZZI, 2013, [1801], p. 163). É como se ele quisesse dizer que não há saber sem saber-fazer. Mas a aquisição do saber pelo saber-fazer tem um processo a seguir.

De acordo com Pestalozzi (2013, [1801], p. 167), “o mecanismo do saber-fazer segue absolutamente o mesmo processo que nos dá o conhecimento" ${ }^{28}$. Como esse processo se configura? Vejamos.

A massa inteira dos nossos conhecimentos vem das seguintes fontes: 1 - Das impressões de tudo isso que é colocado em contato com os cinco sentidos.; 2 - De tudo que impressiona nossos sentidos por intermédio da educação [...]; 3 - Da vontade de adquirir ideias e de alcançar, por uma pesquisa autônoma de todos os tipos, as percepções.; 4 - Dos resultados dos nossos esforços e de nossos trabalhos em todas as profissões e em todos os gêneros de atividade que não tem simplesmente por fim a observação.; 5 - Enfim, o conhecimento sensível é analógico, na medida onde ele me ensina a conhecer igualmente as propriedades das coisas que não são nunca alcançadas pelos meus sentidos, mas abstraio a similitude a partir de outros objetos que verdadeiramente chegam à minha sensibilidade ${ }^{29}$ (PESTALOZZI, 2013, [1801], p. 116).

O conhecimento não é algo dado, pronto, acabado. Pelo contrário, ele é elaborado. A criança elabora seu próprio saber e adquire o conhecimento por esse processo saindo das impressões para ao raciocínio. Mas isso não é nada de outra coisa que a aplicação da intuição sensível (ou exterior) e da intuição racional (ou interior). No desenvolvimento intelectual da criança "a memória não pode ser colocada utilmente em ação, desde que ela se baseie sobre uma grande força da intuição interior e exterior, ou seja, sobre uma boa observação e um bom raciocínio"30 (PESTALOZZI, 1826, p. 13). O raciocínio vai se desenvolvendo como arranjos

\footnotetext{
30 "Il [le savoir-faire] résulte du pur développement de ses propres forces et non d'un apprentissage hasardeux."

31 “Je ne dois pas laisser subsistir cette lacune. Du savoir sans savoir-faire: c'est peut-être le présent le plus redoutable qu'un génie malfaisant ait fait à notre génération.”

32 "Le mécanisme du savoir-faire suit absolument le même processus que celui qui nous donne la connaissance."

33 "La masse entière de nos connaissances vient des sources suivantes: 1. De l'impression de tout ce que le hasard met au contact de nos cinq sens. 2. De tout ce qui impressionne nos sens par l'intermédiaire de l'éducation [...]. 3. De ma volonté d'acquérir des idées et de parvenir, par une recherche autonome des moyens de toute sorte, à des perceptions. 4. Des suites de nos efforts et de nos travaux dans toutes les professions et dans tous les genres d'activité qui n'ont pas simplement pour but l'observations. 5. Enfin, la connaissance sensible est analogique, dans le mensure où elle m'apprend à connaître égalemen les propriétes des choses qui ne sont jamais parvenues en réalité jusqu'à mes sens, mais dont j'abstrais la similitude à partir d'autres objets qui sont vraiment parvenus à ma sensibilité."

34 "La mémoire ne peut être mise utilement en action chez lui, qu'autant qu'elle se fonde sur une grande force d'intuition intérieure et extérieure, c'est-à-dire sur une bonne observation et un bon raisonnement."
} 
de observações, comparações e atos de se exprimir sobre as impressões. Das impressões exteriores para as interiores, a criança vai da intuição para o raciocínio.

Qual o papel do professor nesse processo da criança na aquisição do saber pelo saberfazer? Com a resposta, Pestalozzi:

\section{O mestre não pode ser uma pura ferramenta, distribuidor inanimado de uma matéria morta, semelhante à uma máquina, mas ele deve se colocar ao ponto de vista da criança e mover-se em seu sujeito de maneira a passar de uma verdade a outra, de uma descoberta a outra no mesmo ritmo da criança ${ }^{31}$ (PESTALOZZI, 2008, [1808], p. 159).}

$\mathrm{Na}$ pedagogia pestalozziana considerava-se que a criança tem um ritmo que lhe é própria. Quais aspectos informariam o ritmo da criança? Podemos pensar nas disposições e forças naturais, as quais proporcionam as extensões das faculdades morais, físicas e intelectuais que fazem a criança ampliar seu horizonte em todas as direções, como disse Pestalozzi. Para avançar do simples ao complexo, o ritmo da criança é a ponte entre a passagem de um plano para o outro, mas articulando o complexo como uma extensão do simples. Desse modo, o Método de Pestalozzi faz com que o professor e o saber se elevem em conformidade à criança. Contudo, não só o saber elementar, mas também o professor se colocava no ritmo da criança.

Como conduzir o ensino a partir de objetos concretos seguindo o ritmo da criança? Sem titubear, Pestalozzi diria: estabelecendo uma conversa como a criança (PESTALOZZI, 2012, [1818]). Um dos princípios da instrução elementar pestalozziana é a conversação a partir de uma realidade concreta. Trata-se de uma espécie de jogo que se configura entre perguntas e respostas. Por que esse princípio? Porque naquela época esse princípio funcionava como um instrumento pedagógico e psicológico que permitia identificar o grau de maturidade da criança, fazendo-a externalizar o seu saber. A criança só se expressa sobre aquilo que ela quer conhecer ou sobre o que já conhece. Pestalozzi (1826, p. 12) chamava esse ato da criança de capacité intellectuelle. Com a externalização da criança conseguia-se determinar o ponto de partida do ensino, fazendo-o progredir de modo que a descoberta de um novo elemento do saber seja resultado do desenvolvimento da capacité intellectuelle.

A capacité intelectuelle era também parâmetro para graduação dos níveis da instrução. De acordo com Pestalozzi, "os alunos podem passar de uma classe a outra, em função das suas forças e dos seus progressos". E mais: "O conteúdo e o ritmo do ensino são adaptados ao

\footnotetext{
35 "Le maitre ne peut être un pur outil, distributeur inanimé d'une matière morte, semblable à une machine, mais il doit se placer au point de vue de l'enfant et se mouvoir dans son sujet de manière à passer d'une vérité à l'autre, d'une découverte à l'autre au rythme même de l'enfant."
} 
nível de cada classe"32 (PESTALOZZI, 2008, [1808], p. 156). Como o ensino da Aritmética na escola elementar de Pestalozzi foi adaptado ao ritmo da criança? É justamente disso que trata o próximo item...

\section{0 ensino dos elementos da Aritmética na escola elementar pestalozziana}

Preciso explicar algo. Já sabemos que etimologicamente a palavra elementar nos remete aos elementos. Nessa levada, por Aritmética elementar, entendo os elementos da Aritmética - que são os saberes elementares dessa rubrica. Avancemos...

Nos institutos de Pestalozzi, cada escola tinha sua(s) finalidade(s) e um corpus de saberes. Na Escola Primária, trabalhavam-se os primeiros elementos de: linguagem, escrita, cálculo, formas, desenho, geografia, história natural, história civil, religião, moral, canto e ginástica $^{33}$. Ao olhar para o programa de ensino de cada escola, constatei que no instituto de Pestalozzi, o estudo das matérias pelo método intuitivo ocorria por dois processos: um geral e outro específico. O geral se caracteriza pelas atividades intuitivas, isto é, lições criadas a partir das impressões sensíveis das coisas. Em contrapartida, o processo específico se configura pelo próprio caminhar metódico de cada matéria.

De início, a relação entre o professor, o saber e a criança é fundamentada no diálogo, ou melhor, no princípio da conversação. Por meio de questões o professor fazia a criança construir espontaneamente suas respostas. A depender da lição e da matéria, requer-se o tocar, o ver, o cheirar, o ouvir e/ou o degustar. Porém, independente da finalidade, uma coisa é certa: a criança utiliza os seus sentidos e faculdades, analisando os objetos e fazendo abstrações dos aspectos por meio das comparações. Dos fatos para as leis, as noções elementares se formavam.

Após ter dito isso, anuncio o meu objetivo para este tópico: compreender o avanço metodológico no ensino dos elementos da Aritmética pelo método intuitivo pestalozziano ${ }^{34}$.

\footnotetext{
36 “Les élèves peuvent passer d'une classe à l'autre, en fonction de leur force et de leurs progrès. [...]. Le contenu et le rytme de l'enseignement sont adaptés au niveau de chaque classe."

${ }^{37}$ Cf. os cinco volumes da coleção Ecrits sur la Méthode de Pestalozzi, os quais estão anunciados nas referências deste artigo.

${ }^{38}$ Julguei necessário não expor os resultados da análise antes de fazer uma ressalva. Embora saiba que não foi Pestalozzi quem escreveu os tratados sobre a teoria matemática nos seus livros elementares, mesmo assim continuei fazendo referência a ele. A justificativa é a seguinte. Na França, uma lei de 24 de julho de 1793 normatizou: "l'auteur est celui qui signe" (cf. Dictionnaire encyclopédique du Livre, 2002, p. 184). À época, o governo da Suíça conservou a legislação francesa no que tange os direitos dos autores. Como alguns livros de Pestalozzi foram compostos de cartas assinadas por ele, então conservou-se a sua autoria. Isso porque a parte da teoria matemática era escrita por um dos seus colaboradores e ex-aluno chamado Johann Joseph Schmid (1786 1851). Disse o próprio Pestalozzi: “je déclare donc que je ne possède personnellement ni connaissances
} 
Antes porém, vamos rapidamente analisar as recomendações para o ensino dos elementos da Geometria, a fim de acentuar as diferenças nos processos de ensino a partir de um mesmo método intuitivo.

Nos institutos de Pestalozzi, as matérias se encadeavam formando um sistema de subordinação. Para ele, o ensino da leitura está subordinado à aprendizagem da linguagem; a escrita (ou seja, a caligrafia) está subordinada ao ensino do desenho; este permanece encadeado e subordinado à arte de medir; esta por sua vez é construída pelo estudo da forma (PESTALOZZI, 2013, [1801]). Por assim pensar, os elementos da Geometria eram estudados a partir da forma e da medição, bem como do desenho linear e do desenho artístico sendo matérias independentes, mas subordinadas e articuladas às primeiras. Pelo método intuitivo a criança começava a estudar os elementos da Geometria a partir da forma. Segundo Pestalozzi (2013, [1801], p. 116), “o estudo da forma pressupõe a consciência da percepção dos objetos figurados, [...]"35. Mais adiante, ele sentenciou: "A consciência de minha percepção dos objetos formados dá origem à arte da medida"36 (p. 117). As relações entre as formas pela arte da medida resultava na arte do desenho.

Algo precisa ser esclarecido. Pestalozzi atribuía o qualificar de arte para a produção intelectual na construção do saber. Porém, na sua pedagogia, a intuição sensível antecipa e manifesta a produção intelectual. Daí a necessidade de elevar a intuição sensível a outro nível, ou seja, à arte da intuição, mas se preferir, intuição interior. Desse modo, quando ele utilizava as expressões arte da medida, arte do desenho, arte do cálculo..., referia-se a uma produção intelectual inicialmente impulsionada pela intuição sensível, em outra palavras, a consciência das impressões recebidas. A pergunta é: como descobrir que tipo de consciência a criança está tendo das impressões? Só há uma saída: pedir para que ela externalize suas percepções, quer oralmente, quer por escrito. É nessa externalização que ela constrói o saber pelo saber-fazer. Vamos ao exemplo.

mathématiques, ni facilité pour les calculs. Mais c'est justement ce manque de mérite et de savoir que m'a fait porter un attention plus scrupuleuse sur les procédés psychologiques qui conduisent à cette science, [...]. L'exposé théorique des mathématiques, par des livres élèmentaires, et l'enseignement de cette théorique dans mon institut, sont l'ouvrage d'un de mes élèves, de M. Schmid, [...].” (PESTALOZZI, 1826, p. 9). Este relato de Pestalozzi foi também uma estratégia. Com Schmid morando em Paris desde 1825, o pedagogo suíço encontrou nisso uma nova oportunidade de fazer circular em Paris o seu método intuitivo. Foi o que aconteceu. De 1826 a pelo menos 1848, Schmid difundiu em Paris o sistema de ensino de Pestalozzi para o estudo da matemática. Um dos estabelecimentos onde ele ensinou chamava-se l'Institut Morin. Um dos últimos escritos de Schmid sobre o ensino de matemática pelo método de Pestalozzi foi Introduction des mathématiques dans l'instruction populaire, de 1848 .

39 "L'étude de la forme présuppose la conscience de la perception des objets figures, [...]."

40 "La conscience de ma perception des objets formés donne naissance à l'art de la mesure." 


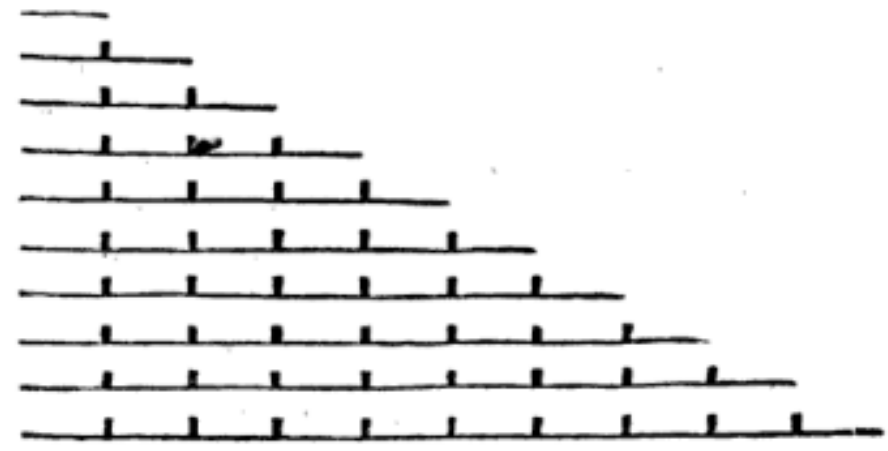

Figura 1 - Tábua para o ensino de Forma pelo método intuitivo de Pestalozzi Fonte: CHAVANNES, 1805, p. 61.

Inicialmente, o propósito da atividade é fazer a criança observar que a primeira linha reta é mais curta do que a segunda; esta também é mais curta que a terceira, e assim sucessivamente. Depois, mostrar que a segunda linha é dividida em duas parte iguais por um ponto; a terceira dividida por dois pontos, e assim sucessivamente. Nota-se que o arranque para o estudo da forma é a linha reta ${ }^{37}$. Para Pestalozzi (1826, p. 15), “um dos problemas mais simples será fazer tirar da criança uma linha reta, [...]"38. A partir de uma linha reta, a espontaneidade indicaria o ritmo do estudo. Um dos primeiros exercícios é perguntar para a criança o que se faz com uma linha. Ao observar a tábua, ela tem condições de dizer que uma linha reta pode ser prolongada, recuada e dividida.

Para entrar na arte da medida, pede-se à criança que reproduza uma linha reta. Essa atividade deve ser repetida até o aperfeiçoamento da noção de demissão. Após isso, ao acrescentar outras linhas retas na atividade, as noções de posições (horizontais, verticais, paralelas e não paralelas) são produzidas. Mas ainda não se explica tais noções. O próximo exercício é solicitar que a criança indique onde se pode encontrar tais posições das retas, a fim de familiarizar as noções observadas (PESTALOZZI, 1826). Só depois, nomeiam-se as posições entre as retas.

Da observação para a reprodução, as relações entre as retas são pesquisadas e construídas pela criança. A atividade com mais de uma linha reta é utilizada para formar outras noções. Linhas retas na paralela contadas por outra(s) reta(s) dariam as noções de ponto e ângulo. Depois de aprender as noções de linhas horizontais, verticais, paralelas, não

\footnotetext{
${ }^{41}$ Nos escritos de Pestalozzi sobre a aplicação do seu método no ensino das matérias nos seus institutos, ele disse que o estudo de Forma começa pela linha reta (Cf. Pestalozzi, 2011, [1801]; 2008, [1802]; 1826). Porém, ao consultar diferentes relatórios e livros produzidos por pessoas que vivenciaram de algum modo o cotidiano escolar nos institutos de Pestalozzi constatei que o ensino de Forma começa pelo ponto (Cf. Mérian, Grégoire e Frédéric, 1810; Jullien, 1818b). O livro de Chavannes (1805) foi o único que indicava o início do estudo de Forma através da linha reta (Cf. figura 1 deste texto). Essas diferenças são as apropriações do método de Pestalozzi pelos autores dos escritos. Dado a isso, optei por seguir as indicações do próprio Pestalozzi.

42 "Un des problèmes les plus simples sera de faire tirer par l'enfant une ligne droite, [...]."
} 
paralelas, ponto e ângulo, o passo seguinte é formar uma superfície com linhas retas. Disse Pestalozzi (1826, p. 17, grifo do autor), “com 3 linhas retas podemos formar uma superfície nomeada de figura" ${ }^{39}$. Nenhuma figura é mostrada à criança. Ao dar certo número de linhas retas, pede-se que a criança reproduza as formas dos objetos que conhece.

Ao construir as figuras, ela já está na arte do desenho. Pois, segundo Pestalozzi (2013, [1801], p. 118), “desenhar é determinar por linhas a forma cujo o contorno e o conteúdo foram determinados com exatidão e precisão de uma completa capacidade de medir" ${ }^{\circ 4}$. Cada figura formada recebe um nome e, como isso, vai-se construindo as noções de triângulo, quadrilátero (paralelo e não paralelo), paralelogramo. Sempre fazendo perceber as diferenças nas formas das figuras não só pelo nome, mas observando através de outros elementos como o número de linhas, de pontos, as posições entre elas e os ângulos. Entre a observação e a representação das formas dos objetos as regras e as propriedades das figuras são elaboradas. Para Pestalozzi (1826, p. 20), “dessa maneira essas formas nela [na criança] se inculcam e chegam da intuição exterior à intuição interior, ou seja, da sua capacidade de observação à sua capacidade de raciocínio"

As mesmas atividades são utilizadas para reproduzir as linhas curvas. Isto é, mostrar uma linha curva, pedir para desenhar e dar exemplos de coisas que tem linhas curvas. $\mathrm{O}$ pedagogo suíço considerou que "a superfície plana e a superfície esférica são suscetíveis de serem tratadas da mesma maneira que as linhas retas e curvas. O processo que deve seguir aqui é tão idêntica com esse guiado na busca e observação das linhas, que uma exposição mais ampla se torna supérfluo" ${ }^{42}$ (PESTALOZZI, 1826, p. 21-22). Na vida cotidiana, a criança é rodeada por objetos diversos que tem formas distintas. Por isso, "a observação dessas diferenças lhe fornece as noções de ponto e linha, seja reta, seja curva, do espaço plano e da superfície esférica; todas essas noções fornecem o fundamento sobre o qual se baseia essa instrução" ${ }^{43}$ (PESTALOZZI, 1826, p. 15). Vamos tentar acompanhar a configuração do processo de ensino que balizava o estudo dos elementos de Geometria desde a linha reta até a superfície esférica.

\footnotetext{
43 "Avec 3 lignes droites on peut former une surfasse nommée figure."

44 "Dessiner, c'est déterminer par des lignes la forme dont le contour et le contenu ont été déterminés avec exactitude et justesse par une capacité achevée de mesurer."

45 "De cette manière ces formes s'inculqueraient en lui, et arriveraient de l'intuition extérieure à l'intuition intérieure; c'est-à-dire de sa capacité d'observation à sa capacité de raisonnement."

46 "La surface plane et la surface sphérique sont susceptible d'être traitées de la même manière que les lignes droites et les lignes courbés. Le procédé qu'il doit suivre ici est tellement identique avec celui que l'a guidé dans la recherche et l'observation des lignes, qu'un exposé plus ample devient superflu."

47 "L'observation de ces différences lui fournit les notions du point et de la ligne, soit droite, soit courbe, de la surface plane et de la surface sphérique; toutes ces notions forment le fondement sur lequel se base cette instruction."
} 
De início, nada de escrever, apenas observar. A primeira noção de medida é elaborada pelo julgamento das impressões de linha reta (cf. Figura 1). A arte de medir se caracteriza com os exercícios de reprodução da linha reta. As atividades com várias linhas retas fazem emergir as noções de ponto, posições e ângulos. Esses são os elementos que formam uma figura. Pedia-se que com várias linhas reproduzisse a forma de objetos conhecidos. Depois, nomeiam-se tais figuras. Trata-se de uma atividade que induz a criança a construir dois saberes: o saber distinguir e o saber classificar tanto as figuras, como os objetos de acordo com as dimensões e propriedades. Isso implica o desenvolvimento de quatro faculdades: observação, composição, comparação e abstração. Trata-se de um estudo dos elementos da forma pelo método analítico pestalozziano. Disse ele:

\begin{abstract}
Nos exercícios sobre os elementos da forma meus colaboradores têm restaurado com grande êxito, amplamente, o que os antigos chamavam de método analítico, procedimento que consiste na solução de problemas, apresentá-los à base de uns casos concretos ao invés de considerá-los em abstrato, e explicar de onde provém em lugar de nos limitarmos a constatar a sua existência ${ }^{44}$ (PESTALOZZI, 2012, [1819], p. 128, grifos do autor).
\end{abstract}

As construções das figuras direcionavam os estudos para a arte do desenho. A ardósia e o lápis eram os únicos materias utilizados. Todo desenho era feito à mão livre. Não se utilizava nem régua, nem compasso, nem transferidor (CHAVANNES, 1805; JULLIEN, 1812a e 1812b). Para Pestalozzi (2008, [1802]), ao produzir desenho à mão livre, a criança se eleva a um nível jamais alcançado pelos homens que recorrem a tais instrumentos. Como o método intuitivo visa o desenvolvimento das forças do espírito humano, então o uso de instrumentos geométricos reduz o desabrochar e o aperfeiçoar dessas forças. A repetição das observações era o recurso pedagógico no treino dos olhos. Com o coup d'oeil (golpe de vista) os alunos capturavam as medidas e desenham à mão livre para também treinar as mãos. $\mathrm{O}$ golpe de vista era um processo que extraia a primeira noção de medida pelos olhos. A reprodução das medidas dos objetos não era nada de outra coisa que a capacidade de imprimir na ardósia as formas desses objetos.

Seguia-se o mesmo procedimento tanto no desenho linear ${ }^{45}$ (visando o aperfeiçoamento das mãos e dos olhos nas construções geométricas) como no desenho artístico (objetivando o desenvolvimento da imaginação). Por que o mesmo procedimento?

\footnotetext{
48 "En los ejercicios sobre los elementos de la forma mis colaboradores han restaurado de nuevo y con grande éxito, ampliándolo, lo que los antiguos llamaron el método analítico, procedimiento que consiste, en la solución de problemas, en plantearlos a base de unos casos concretos en vez de considerarlos en abstracto, y en explicar de dónde provienen en lugar de limitarnos a constatar su existencia."

49 "Touts les enfants pratiquent le dessin linéaire dans le cadre de l'étude des formes, [...]."
} 
Por dois motivos: $1^{\circ}$ ) porque a finalidade não é nem formar um desenhista técnico nem um artista, mas despertar as forças e desenvolver as faculdades naturais. Para isso, os exercícios metódicos para o treino dos olhos e das mãos colocariam em marcha tal finalidade; $\left.2^{\circ}\right)$ o ensino de desenho nessas duas perspectivas mostra claramente que Pestalozzi pensou a mesma sistematização tanto para os elementos da ciência (Geometria) como para os da Arte. E mais: o ensino do desenho artístico tinha também como fim despertar na criança os sentidos de belo e bonito ${ }^{46}$. Tais sentimentos para Pestalozzi são manifestados pela intuição interior. Tratam-se de elementos do desenho artístico que não se assentam em nenhum princípio a não ser a vida interior.

$\mathrm{Na}$ instrução elementar de Pestalozzi, os estudos das relações de forma até os de desenho configuram o "curso ordinariamente chamado de geometria" p. 28). Das formas para os desenhos, as verdades geométricas eram construídas paulatinamente. Tais verdades, como se viu, resultam das combinações de duas perspectivas: a intuição exterior com a interior. $\mathrm{O}$ ritmo de desenvolvimento intelectual jogava papel importante na elaboração das combinações. Aos 8 anos, “a criança ainda é suscetível, à essa idade, ao raciocínio sobre os objetos físicos; as operações geométricas só podem ser compreendidas pelas combinações intelectuais; então que essas combinações sejam fornecidas à criança pela intuição exterior" ${ }^{\circ 8}$ (PESTALOZZI, 1826, p. 28). No método intuitivo pestalozziano, cada linha, cada medida, cada propriedade, cada desenho, cada figura é uma produção da inteligência impulsionada pelas impressões sensíveis. Em resumo: os saberes geométricos são construções intelectuais que vai da observação para o raciocínio.

Em relação aos elementos da Aritmética, o método intuitivo de Pestalozzi confere múltiplas facetas ao estudo dessa matéria. Mas, não é ao acaso. Para se ter uma ideia do que estou falando, acompanhem. Inicialmente, a noção de número é uma unidade sentida caracterizada pelo manuseio dos objetos concretos. Cada objeto ou grupo de objetos é representado por um número aprendido oralmente. Posteriormente, a noção de número é transformada numa unidade visível emergida da visualização de traços nas tábuas. Por fim, a noção de número torna-se uma unidade gráfica representada na forma de traços e de algarismo. O cálculo segue a mesma ordem lógica. Vamos esclarecer as coisas.

\footnotetext{
${ }^{50}$ Cf. Pestalozzi (2013, [1801]).

51 "Cours ordinairement appelé géométrie."

52 “L'enfant n'est encore susceptible, à cet âge, que de raisonnements sur des objets physiques; les opérations géométriques ne peuvent être comprises que par des combinaisons intellectuelles; il faut donc que ces combinaisons soient fournies à l'enfant par l'intuition extérieure."
} 
De acordo com Pestalozzi (2013, [1801], p. 132), "toda a aritmética se reduz à união e à divisão de várias unidades" ${ }^{\text {"49 }}$. Diz-se que o número é uma abreviação do cálculo, o qual é também uma condensação de toda a Aritmética. Como o número não é sempre uma unidade inteira, então há ainda o cálculo das transformações do número. Desse modo, o ensino dos elementos da Aritmética pelo método intuitivo é apresentado em duas partes: $1^{\text {a }}$ ) as relações entre as unidades inteiras (cálculo); $2^{\mathrm{a}}$ ) as diversas relações das partes das unidades (frações). Ele chama de Aritmética as relações entre os números, as quais caracterizam a arte do cálculo. Mas, tudo começa com a noção de número. Como ensinar à criança a noção de número? Resposta: basta dispor objetos em grupos ante os sentidos e contá-los. Acompanhem:

\begin{abstract}
Começamos o ensino de aritmética precisamente assim:
Apresentamos de início à criança dois objetos, os contamos, depois ela conta por si: 1 e 1 fazem 2, 2 vezes 1 fazem 2. Em seguida, apresentamos três objetos, e dizemos: 1 e 1 e 1 fazem $3 ; 3$ vezes 1 fazem 3. O Método começa então por mostrar à criança, intuitivamente, isso que são 2,3 , 4, etc., e dos objetos deve reconhecer o número (2, 3,4 , etc). Mas nesse primeiro exercício apresentam-lhe somente um dois, somente um três, etc., cada número é composto de unidades. ${ }^{50}$ (PESTALOZZI, 2008, [1802], p. 58).
\end{abstract}

Unidade é isso que permite contar os objetos. Número é a unidade dos objetos. Dizendo de outro modo: número é a relação entre unidade e a quantidade de objetos. O estudo tem como ponto de partida o número $u m$, ou melhor, um só objeto ${ }^{51}$. Por isso, um e um são dois objetos. Dois é a união de duas unidades um. A criança aprende a noção de número como uma intuição exterior. Esse primeiro exercício tem como propósito exercitar a capacidade de nomear cada unidade com as palavras um, dois, três..., sempre associando aos objetos. Tratase no fundo de reconhecer o significado quantitativo dos números. Em seguida, apresentam-se grupos de objetos com quantidades distintas. Pede-se que forme grupos com unidades equivalentes a partir de combinações diferentes. A comparação entre os grupos com iguais e desiguais quantidades induz a criança a perceber as primeiras noções de mais e menos. Por quê? Porque para equiparar as quantidades a primeira coisa é perceber que um grupo tem mais ou tem menos unidade(s) em relação aos outros. Sendo assim, a criança é convidada a criar sua metodologia para acrescentar ou retirar unidade(s) de um grupo qualquer para torná-lo

\footnotetext{
53 "Toute l'arithmétique se réduit à l'assemblage et à la division de plusieurs unités."

54 "On commence l'enseignement de l'arithmétique précisément ainsi: on présente d'abord à l'enfant deux objets, on les compte, puis il les compte lui-même: 1 et 1 font 2, 2 fois 1 font 2. Ensuite on présente trois objets, et on dit: 1 et 1 et 1 font 3, 3 fois 1 font 3 . La Méthode commence donc par montrer à l'enfant, intuitivement, ce que sont 2, 3, 4, etc., et des objets dont il doit reconnaître le nombre $(2,3,4$, etc.). Mais dans ce premier exercice, on lui présente seulement un deux, seulement un trois, etc., et chaque nombre n'est composé que d'unités."

55 “[...] le nombre un doit être considéré comme le point de départ de tout calcul et comme le fondement de la méthode de perception pour toutes les transformations de nombre, [...]" (PESTALOZZI, 2013, [1801], p. 135, grifo do autor).
} 
equivalente a outro. Determinam-se desse modo as relações entre os números. "Assim, para a criança, os números são meramente grupos de objetos materiais" ${ }^{\text {52 }}$ (PESTALOZZI, 1826, p. 36).

Mas nem sempre os números aparecem como objetos materiais. A consciência de mais e de menos não emerge somente com o agrupar e desagrupar os objetos móveis. Tem-se, contudo, a necessidade de uma segunda etapa: retirar a criança do contato com as coisas móveis e fazê-la visualizar traços que representam também as unidades. É o momento de direcionar o estudo a partir da tábua de unidades, afinal as imagens continuavam transmitindo as impressões sensíveis de número. Segue abaixo.

\begin{tabular}{|c|c|c|c|c|c|c|c|c|c|}
\hline \multicolumn{10}{|c|}{ PLANCHE I. } \\
\hline 1 & 1 & 1 & 1 & 1 & 1 & 1 & 1 & 1 & 1 \\
\hline II & II & II & II & II & II & II & II & II & $\|$ \\
\hline III & III & III & III & III & III & III & III & III & III \\
\hline IIII & IIII & IIII & IIII & IIII & IIII & IIII & IIII & IIII & IIII \\
\hline IIIII & IIIII & IIIII & IIIII & IIIII & IIIII & IIIII & IIIII & IIIII & IIIII \\
\hline ||IIII & IIIIII & \|\|\|\| & IIIIII & IIIIII & IIIIII & \|\|\|\| & $\||\|| \mid$ & $\||||| \mid$ & $\|1\|\|\|$ \\
\hline$\|||||||$ & IIIIIII & IIIIII & $\|||||||$ & IIIIII & IIIIIII & IIIIIII & IIIIIII & IIIIIIII & $\||\||\||$ \\
\hline|||||||| $\mid$ & $\||\||\|\mid\|$ & $\||||||| \mid$ & $\||||||| \mid$ & |1||||||| & |||||||| $\mid$ & $\|||||||||$ & |||||||| $\mid$ & ||||||||| & ||11||||| \\
\hline|||||||||| & |||||||||| & |||||||||| & ||||||||||1 & IIIIIIII & |||||||||| & $\| 1||||||||$ & IIIIIIIII & | IIIIIIIII & ||I||||||| \\
\hline ||||||| & |||||||||| & ||||||||||| & |IIIIIII! & ||1||||||||| & 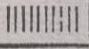 & ||||||||||| & |I||||||||| & |||||||||| & |HIHIIIII \\
\hline
\end{tabular}

Figura 2 - Tábua I elaborada por Pestalozzi: noções de unidades Fonte: CHAVANNES, 1809, p. 204.

Na direção horizontal da tábua, percebe-se que ela está dividida em dez fileiras e dez traços. Cada fileira é composta por dez quadradinhos ${ }^{53}$, os quais contêm a quantidade de traços de acordo com a posição da fileira. A quinta fileira é composta por dez quadrados, cada um com cinco traços, representando a unidade cinco. A terceira também tem dez quadrados, cada um com três traços, dando a ideia da unidade três. O mesmo plano metodológico compõe as oito fileiras restantes. Ainda na direção horizontal, tem-se em cada fileira a ideia de reunião e parte das unidades. A primeira fileira é composta por dez quadradinhos com um traço cada; logo, a reunião desses traços resulta na noção da unidade dez. Na sétima fileira cada traço representa a sétima parte de sete. Vou explicar: se pegarmos dois traços da fileira sete, temos duas vezes a sétima parte de sete.

Na direção vertical, passamos a olhar não mas as fileiras, e sim as linhas de cima para baixo que mostra o aumento das unidades a cada linha. Já de baixo para cima, nota-se a diminuição das unidades a cada linha. $\mathrm{O}$ uso dessa tábua admitia dois objetivos: $1^{\circ}$ ) exercitar

\footnotetext{
56 "Ainsi, pour l'enfant, les nombres ne sont que des groupes d'objets matériels."

${ }^{57}$ Os termos "quadradinhos" e "fileira" são utilizados apenas para tentar melhor explicar.
} 
a capacidade de ver o traço como unidade; $2^{\circ}$ ) estabelecer as relações entre as unidades. Para o alcance do primeiro objetivo, pedia-se que reproduzisse quatro traços na ardósia e escrevia o algarismo 4; cinco traços e escrevia o algarismo 5, etc. De início, a atividade ia de 1 até 10. Reproduzir traços era também o momento de escrever algarismos. As relações entre os números caracterizam a arte do cálculo. A partir da tábua, o estudo do cálculo combina a intuição exterior com a intuição interior. Fazia-se por exemplo a seguinte questão: "quantas 37 vezes um são vezes 5?" 54 (CHAVANNES, 1805, p. 32). Ao observar a tábua, a criança construiria a resposta. Saibamos como: ela iria para a quinta fileira e contaria 7 vezes os quadradinhos com 5 traços que são 35; para formar 37 vezes 1, ela avançaria mais dois traços do quadradinho seguinte. Nessa dinâmica, o professor faria questões envolvendo as operações e os alunos olhando para tábua executavam o cálculo sem a necessidade de escrever os signos $(+,-, \times, \div)$.

Nas ausências de fórmulas e regras dadas a priori $^{55}$, os exercícios familiarizavam a criança com a arte do cálculo. Com esse processo de ensino o cálculo não é um trabalho da memória, ou como disse Pestalozzi um saber-fazer mecânico e rotineiro, mas um produto da observação clara e consciência das relações entre os números. Essa é a forma simples e elementar do cálculo (PESTALOZZI, 2013, [1801]). Não qualquer cálculo, mas aquele denominado de cálculo mental. A primeira vez que Pestalozzi mencionou a expressão cálculo mental foi em $1802^{56}$. Esse saber é um exemplo claro de que pedagogia também cria saberes escolares. Pois, no estudo dos elementos da Aritmética pelo método intuitivo pestalozziano, o cálculo mental era praticado antes mesmo do cálculo escrito (com algarismos e signos). Tratase de um saber calcular que não dependia da escrituração dos números. $\mathrm{O}$ aluno anuncia as respostas oralmente. Trata-se de um raciocínio produzido a partir de objetos e/ou traços e não de algarismos. O que não requer o uso da ardósia e lápis.

Ao praticar numerosos exercícios a partir da tábua I, a criança começaria a perceber que cada número é formado por unidades, seus múltiplos e submúltiplos. A fim de sintetizar as combinações para exprimir grandes números, insere-se o cálculo com algarismos. Nessa

\footnotetext{
58 "Combien 37 fois un sont-ils de fois 5 ?"

${ }^{59}$ Tem-se aqui um princípio fundamental do método intuitivo pestalozziano. Segundo Hippolyte Léon Denizard Rivail, discípulo de Pestalozzi, (1824, p. XI, grifo do autor), "Tel est un autre principe fondamental de notre méthode: L'élève doit découvrir les règles lui-même. [...]. Il a vu, observé, et de ses observations il a déduit des principes". [Tal é outro princípio fundamento de nosso método: $O$ aluno deve descobrir as regras por si. [...]. Ele viu, observou, e das suas observações ele deduz os princípios].

${ }^{60}$ Estou levando em consideração os escritos que tive acesso (Cf. as referências deste artigo). Nos escritos de Cavannes (1805), Mérian, Grégoire e Frédéric (1810), Jullien (1818a e 1818b) e Rivail (1824), a expressão aparece como calcul de tête. Para não proporcionar uma tensão entre documentos originais e traduções, optei por chamar de cálculo mental (expressão que aparece na tradução do texto de Pestalozzi de 1802).
} 
ação conjunta da observação da tábua I e da escrita dos algarismos, tem-se a base de uma profunda e indestrutível consciência do sistema decimal (PESTALOZZI, 2008, [1802]). Até aqui as relações entre os números foram estudadas por unidades inteiras. Familiarizada com o saber calcular, a criança avançava nos estudos rumo ao manejo com as partes das unidades, isto é, os números como frações. Em se tratando do estudo da fração, Pestalozzi disse: “A linha reta é ainda aqui o meio mais simples e o mais fácil, aquela que se presta melhor à observação e à execução" ${ }^{\circ 7}$ (PESTALOZZI, 1826, p. 46). Pelo método intuitivo, o estudo da forma tornou-se a base para as lições de frações. Uma linha reta é uma unidade inteira. Dividir uma linha reta em medidas iguais é fazer a criança observar as partes ou frações de uma unidade (Cf. figura 1). Assim como ocorreu no estudo de número, as frações também tinham uma tábua.

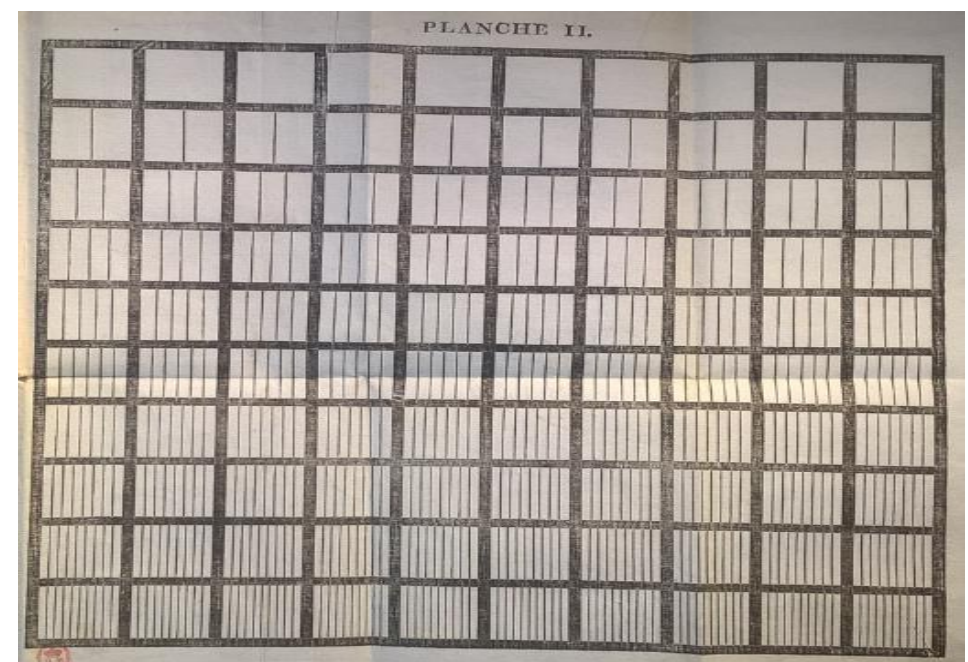

Figura 3 - Tábua II elaborada por Pestalozzi: noções de unidades divididas (frações) Fonte: CHAVANNES, 1809, p. 205.

Se na primeira tábua a noção de número é explorada por traço(s) presente(s) nos dez quadradinhos de cada fileira, agora os próprios quadradinhos representam a ideia de unidade. Em outras palavras, cada quadradinho ilustra a ideia de que toda unidade pode ser dividida em partes iguais. Por conseguinte, a composição de uma unidade pode ser representada através da reunião de suas partes iguais. Na primeira fileira, o quadradinho representa a noção de uma unidade inteira. Já na terceira fila, tem-se ilustrada uma unidade dividida verticalmente em três partes iguais - cada parte, neste caso, esboça a terça parte de uma unidade.

Ao analisar a tábua II, tanto horizontal como verticalmente, nota-se que a noção de unidade inteira e fracionária também pode ser elucidada pela ideia de espaço. Por exemplo, olhando-a pela direção vertical, percebe-se que de cima para baixo os espaços entre as partes

\footnotetext{
${ }^{61}$ "La ligne droite est encore ici le moyen le plus simple et le plus facile, celui qui se prête le mieux à l'observation et à l'exécution."
} 
vão diminuindo. Já de baixo para cima, eles vão aumentando. Para além de outros aprendizados, essa tábua II propícia a criança aprender, através de cada quadradinho, quantas partes iguais são necessárias para compor uma unidade. À medida que o estudo vai avançando as frações vão sendo representadas por algarismos $\left(\frac{1}{2}, \frac{1}{3}, \frac{1}{4} \ldots\right)$.

Para identificar a principal diferença nos processos de ensino entre os elementos da Aritmética e os da Geometria é preciso olhar para as respectivas finalidades de cada matéria. As noções geométricas seriam construídas a partir da reprodução dos elementos da forma: a linha reta, ângulo e ponto. Saber medir e saber desenhar desempenham papéis fundamentais. Dado a isso, uma das finalidades dos exercícios da forma e do desenho era aperfeiçoar as mãos e os olhos, de modo que cada propriedade geométrica seja uma verdade construída pela capacidade de julgamento e reprodução da altura, largura e espessura. São elementos que se adquirem inicialmente pelo olhar. Isso explica o ponto de partida do estudo das formas: a observação e, depois, a reprodução de uma linha reta.

Diferentemente, a noção de número é uma consciência clara da manifestação das impressões sensíveis que emerge com a contagem dos objetos móveis. Esses apontamentos encontram respaldo quando Pestalozzi disse que para a criança os números são meramente objetos materiais (inserir fonte). Isso explica o ponto de partida do estudo dos números: manusear e contar objetos reais. Agrupar e reagrupar os objetos são processos que revelam as combinações reais entre as quantidades. Contudo, essas combinações são a base do cálculo. Daí, Pestalozzi considerou a Aritmética como uma abreviação do cálculo e este uma extensão das relações entre os números. Do início ao fim, o ensino e aprendizado dos elementos da Aritmética tem a finalidade de desenvolver o raciocínio (PESTALOZZI, 2013, [1801]).

Do concreto ao abstrato, o método intuitivo pestalozziano reduziu os elementos da Geometria e da Aritmética aos processos mais simples e mais elementares. Como se caracterizava o concreto? E o abstrato? Disse Pestalozzi (2013, [1801], p. 59, grifos do autor): “o exercício que consiste a praticar com as crianças o início do cálculo por meio de objetos materiais, ou ao menos por meio de pontos que os representam, deve assegurar uma base sólida à aritmética toda inteira e preservar seus progressos ulteriores do erro e da confusão" Ao justapor essa citação e as indicações para o início do ensino dos elementos da forma (a ilustração de uma linha reta) e do cálculo (os objetos reais móveis), tem-se claramente que a experiência sensível é o concreto da pedagogia pestalozziana. Amparada nas impressões

\footnotetext{
62 "L'exercice qui consiste à pratiquer avec les enfants les débuts du calcul au moyen d'objets matériels, ou au moins par des points qui les représentent, doit assurer une base solide à l'arithmétique tout entière et préserver ses progrès ultérieurs de l'erreur et de la confusion."
} 
sensíveis, a abstração é um processo do interior da criança no qual ela simplifica/sintetiza as informações que chegam pelos sentidos. Na criança "a formação da faculdade de abstração deve derivar do uso dos seus órgãos e dos membros maduro pelo exercício diário e deve fundar-se nisso"59 (PESTALOZZI, 2003, [1827], p. 194).

\section{Palavras finais sem pretensões de finalizar...}

Pestalozzi sistematizou sua pedagogia num período denominado por Troger e RuanoBorbalan (2015) da "emergência de contra-culturas pedagógicas". O pedagogo suíço era contra a ideia do aluno permanecer sentado, imóvel, calado, autômato, passivo. Para ele, o aluno da escola primária é a criança com uma força ativa e ponto central. Ao professor compete se colocar no ritmo da criança. Pois, o saber que ela adquiri não é algo dado a priori, mas construído. Tudo o que ela aprende é resultado da sua própria atividade. Por isso, o professor não é uma máquina de transmissão do saber. Pestalozzi não era contra a memorização. Pelo contrário, na sua pedagogia a memória tinha papel fundamental.

A memória, quando procede através dos conhecimentos psicologicamente bem graduados, coloca por si mesma em movimento outras faculdades da alma. A memória, combinado as letras difíceis, anima a imaginação; a memória, seguindo as séries de número, fixa o espírito sobre suas relações internas; a memória, inculcando-se de verdades complexas, prepara o espírito a prestar atenção ao simples e ao complexo. ${ }^{60}$ (PESTALOZZI, 2009a, [1799], p. 83).

O pedagogo suíço era contra ao ensino que de início falava diretamente à memória. Para superar isso, a intuição sensível foi considerada o arranque do ensino. Amparados nesse princípio, os saberes elementares da Aritmética foram reduzidos, de algum modo, aos elementos palpáveis, visíveis e acessíveis a todos os sentidos dos alunos.

De acordo com Schmid (1848, p. 7), "é a Pestalozzi que consiste a glória de ter ousado o primeiro a introduzir a matemática (aritmética, geometria, álgebra) nos programas do ensino popular" ${ }^{\prime 61}$. Trata-se, como se viu, de uma Matemática colocada na forma de elementos para a criança aprender desde cedo as noções mais simples, mais elementares. Dessa forma, os elementos da Aritmética eram ensinados nos institutos de Pestalozzi pela experiência sensível. De acordo com um discípulo de Pestalozzi, Hippolyte Léon Denizard Rivail, "a Aritmética

63 "La formación de su facultad de abstracción debe derivar de un uso de sus órganos y de sus membros madurado por el ejercicio diário y debe fundarse en eso."

64 "La mémorie, lorsqu'elle procède à travers des connaissances psychologiques bien graduées, met par ellemême en mouvement les autres facultés de l'âme. La mémorie, en combinant les lettres difficiles, anime l'imagination; la mémoire, en suivant les séries de nombres, fixe l'esprit sur leurs rapports internes; la mémoire, en s'inculquant des vérités complexes, prépare l'esprit à prêter attention au simple et au complexe."

${ }^{65}$ "C'est à Pestalozzi que revient la gloire d'avoir osé le premier introduire les mathématiques (arithmétique, géométrie, algèbre) dans le programme de l'enseignement populaire." 
[do método intuitivo pestalozziano] deve ser considerada não somente como ciência, mas como meio de desenvolver a inteligência da criança, de formar seu julgamento e de lhe habituar a raciocinar com justeza"62 (RIVAIL, 1824, p. V).

\section{Referências}

BRU, M. Les méthodes en pédagogie. 3. ed. Paris: Presses Universitaires de France, 2015. 127 p.

CHALMEL, L. La "Méthode Pestalozzi", une tentation française. In: PESTALOZZI, Johann Heinrich. Ecrits sur la Méthode: Esprit de la Méthode (Volume III). Le-Mont-sur-Lausanne: LEP Editions, 2009b. p. 243-260.

CHAVAnNeS, D. A. Exposé de la méthode élémentaire de H. Pestalozzi. 1. ed. Vevey: Loertscher et Fils, 1805. 203 p.

. Exposé de la méthode élémentaire de H. Pestalozzi (nouvelle édition). 2. ed. Paris: Chez J. J. Paschoud, 1809. 203 p.

CHERVEL, A. História das disciplinas escolares: reflexões sobre um campo de pesquisa. Revista Teoria \& Educação, Porto Alegre, n. 2, p. 177-231, 1990.

FOUCHÉ, P.; PÉCHOIN, D.; SCHUWER, P. Dictionnaire encyclopédique du livre. 1. ed. Paris: Éditions du cercke de la librairie, 2002. 900 p.

JULLIEN, M. A. Esprit de la Méthode d'Éducation de Pestalozzi. Tomo I. 1. ed. Milan: Royale, 1812a. 368 p.

. Esprit de la Méthode d'Éducation de Pestalozzi. Tomo II. 1. ed. Milan: Royale, 1812b. 508 p.

LE GOFF, J. História e Documento/monumento. In: História e memória: tradução Bernardo Leitão. Campinas, SP: Editora da UNICAMP, 1994. p. 17-166 e 535-549.

MÉRIAN, A.; GIRARD, G.; TRECHSEL, F. Rapport sur l'institut de Mr. Pestalozzi à Yverdon. 1. ed. Suisse: Béat-Louis Piller, 1810. 200 p.

MONROE, P. História da Educação. Nova tradução de Idel Becker e Therezinha G. Garcia. Atualidades Pedagógicas (v. 34). 7. ed. São Paulo: Companhia Editora Nacional, 1968. 388 p.

PESTALOZZI, J. H. Cartas sobre educación infantil. 3. ed. Tradução de José María Quintana Cabanas. Madrid, España: Editorial Tecnos S. A, 2012 [1818-1819]. 146 p.

. El canto del cisne. Tradução de José María Quintana Cabanas. 1. ed. Barcelona: Editorial Laertes, 2003 [1827]. 309 p. 2008. $197 \mathrm{p}$.

Ecrits sur la Méthode: Tête, coeur, main (Volume I). Le-Mont-sur-Lausanne: LEP Editions,

. Ecrits sur la Méthode: Industrie, pauvreté et éducation (Volume II). Le-Mont-sur-Lausanne: LEP Editions, 2009a. 181 p.

66 “L'arithmétique doit être considérée non-seulement comme science, mais comme moyen de développer l'intelligence de l'enfant, de former son jugement, et de l'habituer à raisonner avec justesse." 
Ecrits sur la Méthode: Esprit de la Méthode (Volume III). Le-Mont-sur-Lausanne: LEP Editions, 2009b. 265 p.

. Ecrits sur la Méthode: La Méthode à l'épreuve de l'expertise officielle (Volume IV). LeMont-sur-Lausanne: LEP Editions, 2011. 388 p.

. Ecrits sur la Méthode: Comment Gertrude instruit ses enfants (Volume V). Le-Mont-surLausanne: LEP Editions, 2013. 221 p.

. Méthode théorique et pratique de Pestalozzi pour l'éducation et l'instruction

élémentaires (publiée en français par lui-même). 1. ed. Paris: Lassime et Cia., 1826. 135 p.

RIVAIL, H. L. D. Cours pratique et théorique d'Arithmétique, d'après la méthode de Pestalozzi. (Tome premier). 1. ed. Paris: Chez Pillet Ainé (imprimeur-libraire), 1824. 224 p.

ROBERT, P. Dictionnaire de la langue française (Le Petit Robert). Nouvelle édition. Paris: VUEF, 2003. 1129 p.

SCHMID, J. J. Introduction des Mathématiques dans l'instruction populaire. 1. ed. Paris: imprimerie Lacrampe fils et compagnie, 1848. $14 \mathrm{p}$.

SOËTARD, M. La Méthode comme anthropologie pédagogique. In: PESTALOZZI, J. H. Ecrits sur la Méthode: Tête, coeur, main (Volume I). Le-Mont-sur-Lausanne: LEP Editions, 2008. p. 171-186.

Qu'est-ce que la pédagogie? Le pédagogue au risque de la philosophie. 1. ed. Issy-lesMoulineaux: ESF éditeur, 2001. 122 p.

. Johann Pestalozzi. (Coleção Educadores). 1. ed. Trad. Martha Aparecida Santana Marcondes, Pedro Marcondes, Ciriello Mazzetto. Recife: Fundação Joaquim Nabuco, Editora Massangana, 2010. 112 p.

TROGER, V; RUANO-BORBALAN, J. C. Histoire du système éducatif. 4. ed. Paris: Presses Universitaires de France, 2015. 127 p.

TROUVÉ, A. La notion de savoir élémentaire à l'école: doctrines et enjeux. 1. ed. Paris: L'Harmattan, 2008. 293 p.

Submetido em 10 de Abril de 2016. Aprovado em 8 de Dezembro de 2016. 